\title{
Visualization Analysis of Emergency Logistics Research Based on the CiteSpace III
}

\author{
Li Jialing \\ School of management \\ Guangxi University of Science \& Technology \\ Liuzhou, China \\ E-mail: 15177731258@163.com
}

\author{
Liao Zhigao* \\ School of management \\ Guangxi University of Science \& Technology \\ Liuzhou, China \\ E-mail: liaozhigao@126.com \\ * Corresponding Author
}

\begin{abstract}
Emergency logistics level directly affects the control of all kinds of unexpected events. Therefore the emergency logistics got more and more attention of the government, as well as the academic circle. Many researches have been made on emergency logistics, especially review articles. However, there is no literature from the perspective of the visualized analysis. To more about the theory system, research hotspot and frontier of emergency logistics and provide some reference of related research for Chinese scholars, a visualization analysis was made to quantify the related data statistics from WOS, and the main published authors, institutions, highly cited authors, core literatures, research hotspots and frontier through software Cite Space III. The results show that although China is a major contributor of emergency logistics research, there is a imbalance between the frequency of published periodical articles and citation frequency; most research group are independent despite there are multiple research groups; the basic research hot spot during the 2007-2008 has gradually formed; As a branch of logistics, emergency logistics itse If is a burst term, the rest of the frontier is based on the emergency logistics.
\end{abstract}

Keywords- Emergency Logistics; Visualization Analysis; Cooperation Network; Research Hotspot; Research Front

\section{INTRODUCTION}

In recent years, with the rapid development of economy, social contradictions intensify increasingly, emergencies occur frequently and the frequency of natural disasters increased gradually. Emergency of major events tend to cause casualties and property losses, and emergency logistics level directly affect the control of all kinds of unexpected events. Therefore the emergency logistics got more and more attention of the government, as well as the academic circle.

Many researches have been made on emergency logistics, this paper mainly focus on review articles. Search keywords "emergency logistics review" on CNKI (China National Knowledge Infrastructure) and core data base of the Web of Science, a total of 21 review articles have been found (18 articles in Chinese, 3 in English).

Literature in Chinese can be divided into the following three categories according to its research content (1) the first category reviews from the definition, mechanism, research basis with the subject of emergency logistics research review [1-9]; (2) the second are concentrates on material distribution, such as distribution network, routing, vehicle scheduling problem [10-14]; (3) the third is from the angle of the emergency management and supply chain management [15-18].

The literature review in English summarized from different perspective. Dasaklis, Thomas k.et al. (2012) [19] summarized the establishment and management of the supply chain and logistics operation and management from the epidemic situation control perspective. Galindo et al. (2013) [20] made a summary of the research on disaster operation management (DOM) published on OR/MS (operations research/management science journals) on the basis of Altay Green (2006), the results shown that since 2006 the related research didn't make a breakthrough growth. Perrier (2013) [21-22] investigated model and algorithm of the emergency response logistics system in emergency response logistics, from the view of the reliability of fault problem plan and emergency plan level.

All the above literature review about emergency logistics is based on the traditional qualitative method, namely for a certain issue, such as optimization problem, and emergency supplies, etc. to review and make a summary neglect of the research hot spot and tendency, which are difficult to summarize research hot and frontier issues of emergency logistics scientifically.

Information visualization is a kind of bibliometric methods that represent the abstract data by visualization, which is conducive to analyze the data and find rules [23].

There are few researches on visualization analysis in the field of logistic literature, and no scholars use visualization software to make in-depth research on emergency logistics. Therefore, this paper aims to deeply analyze the research state, institution, scholars, and research hot spot and knowledge frontiers of international emergency logistics by mapping knowledge domain through using the Cite Space III software. It is from a new unique visual angle to help scholars know more about the emergency logistics research and provide rational theoretical reference suggestions for the relevant government departments to make a scientific and reasonable emergency logistics planning. 


\section{DATA AND METHODOLOGY}

\section{A. Data Source}

The data in this paper is from Core data collection of Web of Science; we entered the key word Emergency Logistics and searched the articles from 1991 to 2015 on May 25, 2015, obtained 6353 related papers.

\section{B. Data Processing}

In order to delete irrelevant literature and pick up emergency logistics literature to better reflect the theme of the Emergency Logistics areas, we need to sift the preliminary 6353 articles. [24] summarized the top ten subject category logistics literature published, thus we make the following steps (1) choose the ten research direction, such as operational research and management Science, industrial engineering, manufacturing, computer Science, transportation to narrow the field; (2) remove irrelevant categories (medical, public ethics) on the basis of the above, Finally got 441 literature (article 260, Proceedings paper 181).

\section{Methodology}

Cite Space III developed by Dr. Chen from college of information science and technology, the Drexel university, as an analysis tool, can realize automatic clustering and term tag integrating information visualization method bibliometrics methods and data mining algorithm, and can clearly draw a certain period frontier hot spot and development trend in the field of scientific knowledge.

\section{RESULTS AND ANALYSIS}

\section{A. Network Analysis of the Country and Author - Agency Cooperation}

The visualization analysis for emergency logistics coauthors, institutions, and issuing countries can to a certain extent understand the main contribution of the emergency logistics countries, the major scholars, as well as the relationship and close degree between the various research institutions.

a) Country Distribution Network: Highlight all author Select "country" as a node, run Cite Space III software, get country distribution diagram of the emergency logistics. Fig. 1 only represents the countries based on the posting frequency; the size of the font and circle represents quantity of published articles; the bigger it is, the more emergency logistics related literature published on journals. according to the results of the software, the top ten countries are Chinese mainland (153), the United States (95), Taiwan (19), England (19), France (17), Turkey(15), Italy (12), Australia (11), Germany (10), Spain (10) and Italy (10). It is found that China and the United States play amajor part in the emergency logistics research. however, there is little ties with other countries; other European countries have a high degree of cooperation, although the nodes is small, but the lines connected nodes are much more than china.

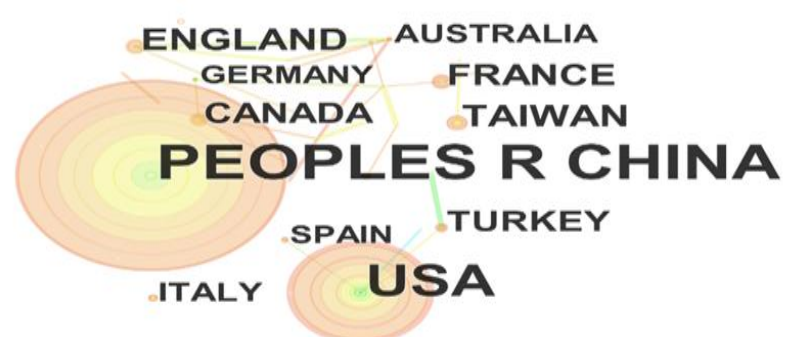

Figure 1. Country Distribution Diagram of the Emergency Logistics Research

b) Author-Institution Network: First, Table 1 lists the related author and institutions respectively according to the post frequency and citation rates through the software. There are six authors and five universities from China during the top eight prolific authors and institutions, which is consistent with the Fig. 1. Cited frequency is an important index used to assess high influence authors of a research field. There are six foreign authors during the eight highly cited authors, and only professor SHEU (JB) from National Taiwan University maintains a high quanity and highly cited amount; The rest of the prolific authors presents an unequal relationship in the frequency and the cited frequency. Although China has made a great contribution to emergency logistics literature, there is still some gap with other countries, especially on the influence. In the future research should pay more attention to the quality and influence of the literature.

TABLE I. AUTHORS, INSTITUTIONS AND HIGHLY CITED AUTHORS

\begin{tabular}{|c|c|c|}
\hline $\begin{array}{c}\text { Author } \\
\text { (frequency) }\end{array}$ & Cited Authors & Institutions \\
\hline $\begin{array}{l}\text { Zhao Lindu } \\
\text { (11) }\end{array}$ & OZDAMAR L(80) & $\begin{array}{c}\text { Southeast University } \\
\text { (11) }\end{array}$ \\
\hline SHEU JB (7) & SHEU JB(63) & $\begin{array}{c}\text { National Taiwan University } \\
\text { (8) }\end{array}$ \\
\hline Zhi-hua hu (4) & YI W(56) & $\begin{array}{c}\text { Shanghai Maritime University } \\
\text { (6) }\end{array}$ \\
\hline $\begin{array}{l}\text { Tan Qing } \\
\text { mei(4) }\end{array}$ & $\begin{array}{l}\text { BARBAROSOGLU } \\
\text { G(54) }\end{array}$ & $\begin{array}{c}\text { South China University of } \\
\text { Technology (6) }\end{array}$ \\
\hline Xiao-hui li (4) & BALCIK B(50) & $\begin{array}{l}\text { University of Texas at Austin } \\
\text { (5) }\end{array}$ \\
\hline Ms. Wang (3) & FIEDRICH F(40) & $\begin{array}{l}\text { University of Madrid Compton, } \\
\text { (5) }\end{array}$ \\
\hline Begona & HAGHNI A(40) & The University of Toronto \\
\hline Vitoriano(3) & & (5) \\
\hline Erhan & ANNYMOUS(39) & Nanjing University of \\
\hline Kutanoglu(3) & & $\begin{array}{l}\text { Aeronautics and Astronautics } \\
\text { (4) }\end{array}$ \\
\hline
\end{tabular}

Select "Author" and "Institution" as the node, other options keep unchanged, and run the Cite Space III, generate the author-institution network, as shown in Fig. 2. It is found that part of the highly frequency authors and institutions are the isolated nodes, which shows that there is less cooperation with other groups. The size of the dot and the font in the Fig.2 stands for the number of emergency logistics research.

According to the results and Fig. 2, there are several cooperation, the two research cooperation networks are: (1) Southeast University team contains Zhao Lindu, Ms. 
Wang, Amy z. Zeng (Worcester polytechnic institute), members of which mostly are from school of systems engineering, logistics management systems engineering department; (2) cooperation composed by SHEU JB (National Taiwan University) and $\mathrm{Hu}$ Zhi-hua (Shanghai Maritime University).Other two teams are (1) cooperation team consisted of B. Vitoriano, M.T. Ortuño and G. Tirado (Universidad Complutense) and F. Liberatore (University of Madrid King Juan Carlos) and M.P. Scaparra (Kent University of Canterbury); (2) PT. Evers (university of Maryland) as the core, consisted of Kefeng Xu (University of Texas at SAN Antonio), Yan Dong (University of Minnesota) and Philip t. Evers (University of Maryland).

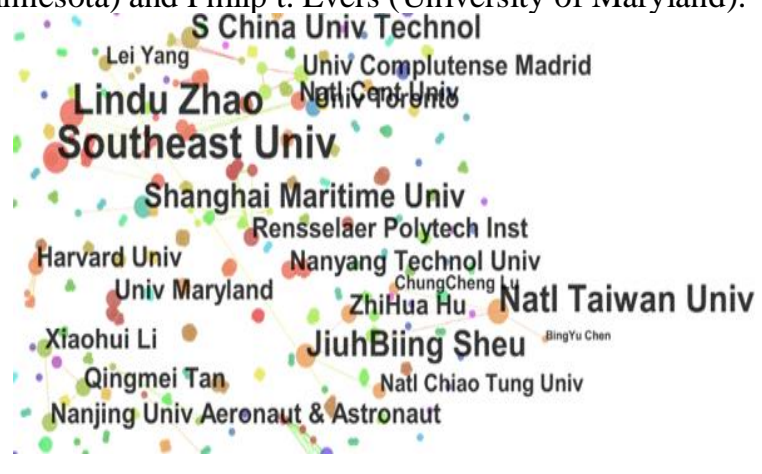

Figure 2. Author-Institution Cooperation Network

\section{B. Research Fronts}

a) Basic Knowledge Analysis of Research Front: Before analyzing research front, it is necessary to make a co-citation analysis (if two literature are cited by the same paper, then there is co-citation relationship between the two cited articles). Fig. 3 is the emergency logistics research front time map based on the cited frequency. You can see the highly cited literature from 1991 to 2015. Highly cited and centricity literature play important role in research front evolution (the higher the centricity of literature is, the greater connection role is). the next some high cited frequency and centricity literature are introduced [26-31].

Haghani A (1996) published Formulation and Solution of a Multi-Commodity, Multi-Modal Network Flow Model for Disaster Relief Operations on Transportation Research Part A (cited frequency 123; centricity is 0.05). The paper proposed a model and two kinds of heuristic algorithms for complex problem networks in disaster assistance management to solve large-scale commodity more with time Windows, and multi-mode network flow. Early emergency logistics research mainly focuses on the model in the 1990s; data used in cases were artificial integrated data. That paper has been got continuous attention from the beginning of the published up to now, and is one of founding literature of the early emergency logistics research.

Fiedrich, F (2000) published Optimized Resource Allocation for Emergency Response after Earthquake Disasters on SAFETY SCIENCE (cited frequency 181; centricity 0.02). This paper puts forward that the first major goal after the earthquake is to minimize the total number of death. There is an important problem in this period is to find the best available operation area to allocated resources. Therefore, a dynamic optimization model is put forward aimed at the problem, which laid a foundation for the later dynamic emergency logistics research.

G Barbarosog caronlu (2004) published A Two-Stage Stochastic Programming Framework for Transportation Planning in Disaster Response on Journal of the Operational Research Society (cited frequency 183, certricity 0.01). It proposed a two-stage stochastic programming model aiming at transporting emergency transport relief goods to the disasters areas based on the simple dynamic models. Resource scheduling is taken as a random state and the resource demand as random parameters, it proposed that the uncertainty caused by vulnerability of the traffic system will affect capacity and supply capacity of logistics network.

OZDAMAR L (2004) published Emergency Logistics Planning in Natural Disasters on ANNALS OF OPERATIONS RESEARCH (cited frequency 150, centricity 0.01 ), which proposed dynamic programming mode used in a natural disaster logistics decision support system. It treated vehicle as commodities and integrated the traditional product flow, and hybrid network vehicle flow problem and vehicle routing problem. The paper innovatively integrated vehicle routing and the traditional logistics network, to some extent, affected the later literature about vehicle routing and traditional logistics network research.

Wei Yi, Linet Özdamar published A Dynamic Logistics Coordination Model for Evacuation and Support in Disaster Response Activities on General Information in 2007 (cited frequency 168, centricity 0.02). On the basis of OZDAMAR L, this paper put forward Location Allocation model based on mixed multi commodity network flow under the condition of disaster response.

Jiuh-Biing Sheu (2007) published An Emergency Logistics Distribution Approach for Quick Response to Urgent Relief Demand in Disasters on Transportation Research Part E (cited frequency 150, centricity 0.03). This paper proposed a hybrid fuzzy clustering optimization algorithm, in order to response to an emergency relief supplies demand and the operation of the joint distribution of emergency logistics. The algorithm can be divided into the affected area classification and relief logistics joint distribution, and the emergency supplies distribution framework was divided into three levels: relief supply area, the distribution area and the affected areas.

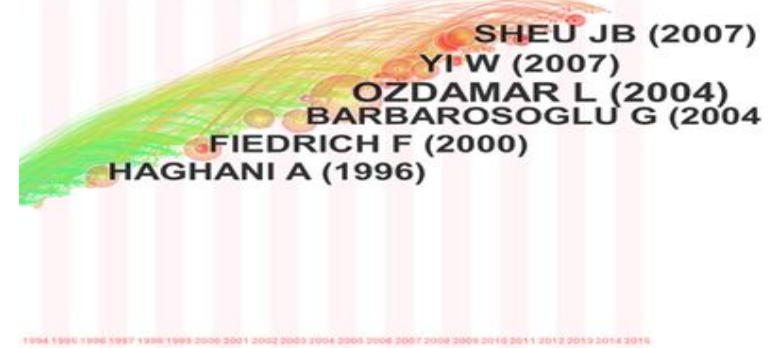

Figure 3. High Cited Literature Time Map of Emergency Logistics

b) Research Hot: To understand the current international emergency logistics research hot, select "keyword" and "term" as the node, "the noun phrases" as the node type, generate keywords co-occurrence graph, 
the Fig. 2. There are multiple hot spots from 1991 to 2015 , such as, emergency logistics/logistics, model, management, system, optimization, humanitarian logistics, Disaster response/Disaster, Disaster relief, evacuation, supply chain et al.

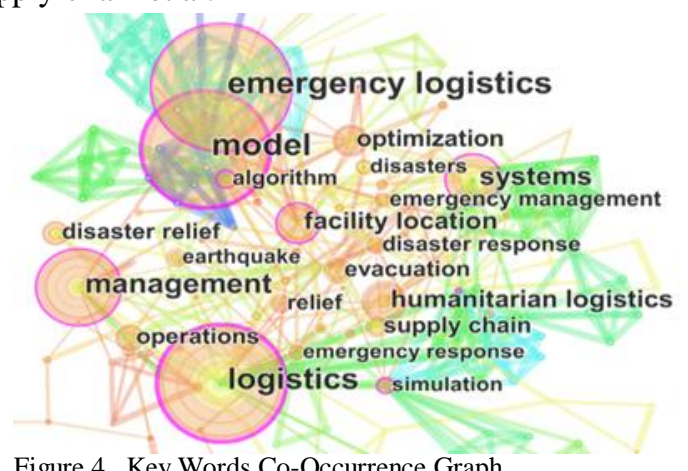

Figure 4. Key Words Co-Occurrence Graph

The size of the ring indicates frequency of the keywords co-occurrence; ring color stands for the publishment year (purple rings are key nodes, which means mediation centricity greater than 0.1 ). The top 10 high-frequency key words are listed in Table 2.

TABLE II. EMERGENCY LOGISTICS RESEARCH HOT WORDS (TOP TEN)

\begin{tabular}{cccc}
\hline Frequency & Key Words & Year & Centrality \\
\hline 68 & model & 2007 & 0.22 \\
66 & emergency logistics & 2003 & 0.24 \\
63 & logistics & 1992 & 0.28 \\
45 & management & 2005 & 0.26 \\
34 & humanitarian logistics & 2009 & 0.08 \\
32 & system & 2003 & 0.09 \\
24 & facility location & 2007 & 0.07 \\
23 & optimization & 2008 & 0.05 \\
20 & disaster relief & 2008 & 0.03 \\
19 & operations & 2007 & 0.07 \\
\hline
\end{tabular}

\section{CONCLUSIONS}

Taking emergency logistics as the research subject, making a quantitative analysis based on the data in Web of Science through Cite space III, This paper represented authors, highly cited authors, institutions network map and analysed the basic knowledge in the process of frontier evolution, hotspot changes, etc. the results are summarized as follows:

China made a great contribution to the emergency logistics research; Zhao Lindu (from Southeast University), Jiuh-Biing Sheu (National Taiwan University), Hu Zhihua (Shanghai Maritime University) are prolific authors; more cooperation needs be strengthened, especially the universities in China.

6 article are analysed from two aspects (the cited frequency and the centricity), which to a certain extent played a positive role in promoting the research on the time window, dynamic analysis, multi-stage and distribution framework,
There are several hot research topics in recent years, such as emergency logistics/logistics, humanitarian logistics, Disaster response/Disaster, Disaster relief, evacuation, supply chain, facility location, earthquake, and operation.

\section{Acknowledgment}

This paper was supported by 1) the outstanding young backbone teachers' training program in higher education institutions of Guangxi, China; 2) Guangxi Philosophy and Social Science Fund (The Grant No. 13BGL009) and 3) The teaching reform project in higher education of Guangxi (No. 2012JGA178).

\section{References}

[1] YIN Chuan-yong. "Analyses the current research on emergency logistics in China", Legal System and Society 05(2007):743-744.

[2] WANG Zhi-ke, LV Zhi-hua. "Research Summary on China's Emergency Logistics", Logistics Sci-Tech 32.06 (2009): 4-6.

[3] GAO Wen-jun,CHEN Ju-hong, HU Fei-hu. "The Retrospect and Prospect of Chinese Emergency Logistics Study”,, Logistics SciTech 08 (2009):6-10

[4] GAN Hong-yun. "Emergency logistics research review", Journal of xiangtan normal university (social science edition) 31.06 (2009):60-61.

[5] SHUAI Guo-rang. "Emergency logistics research review", Oriental Enterprise Culture 18 (2010):233.

[6] YING Jun. "Emergency logistics research reviewe", Logistics SciTech 06(2011):7-10.

[7] ZHANG Jing-xia, ZHANG Zheng. "Summary on Emergency Logistics in Foreign Countries", Logistics Engineering and Management 34.04(2012):93-95+140.

[8] ZHOU Da-peng. "the latest progress and research prospects of Emergency logistics - based on the literature review", Productivity Research 04(2013):194-196.

[9] LI Chuang. "Review on Domesticand Foreign Researchon Emergency Logistics", East China Economic Management 06 (2013):160-165.

[10] MIAO Chen, XU Wei-sheng, WU Qi-di. "A Survey of Large-scale Emergency Relief's Transportation Problem", Journal of XinJiang Vocational University 01(2007):35-38.

[11] CHEN Li-qun. "Review on the Research of Material Distribution in Emergency Logistics", Logistics Sci-Tech, 12(2008):4-6.

[12] YU Qiu-ting, ZHANG Qi-shan. "Emergency distribution network research literature review", Pioneering With Science \& Technology Monthly 04(2012):119-120+123

[13] CHEN Gang, PENG Yong-tao. "research present situation and development direction of disaster relief emergency supplies distribution problem", Railway Transport and Economy,04 (2012):62-66

[14] TAN Xiao-yong, LIU Qiu-ju. "Review and prospect of vehicle scheduling optimization in emergency distribution", Application Research of Computers 09(2012):3212-3215+3220.

[15] LI Ya-bing,QIAO Peng-liang,TAO Jian-biao. "The Domestic and Foreign Emergency logistics management research reviewe", Coal Economic Research 10. (2008)10:44-47.

[16]LIU Man, WU Jia-hao, HE Xin-hua. "The Domestic and Foreign Research Status and Development Trends Based on Emergency Management", Traffic and transportation (academic version) 02 (2013):150-154.

[17] GENG Zhao-xin, LIANG Chen. "Emergency response time of supply chain under information sharing environment research reviewe", China Logistics \& Purchasing 04 (2013):70-71.

[18] PEI Chang-Yong.Emergency logistics management research review. Industrial \& Science Tribune 12.1(2013):126-127.

[19] Dasaklis, Thomas K.; Pappis, Costas P.; Rachaniotis, Nikolaos P. "Epidemics control and logistics operations: A review", 
International Journal of Production Economics 139.2(2012): 393410

[20] Galindo, Gina; Batta, Rajan. "Review of recent developments in OR/MS research in disaster operations management", European Journal of Operational Research 230.2 (2013):201-211.

[21] Perrier, Nathalie; Agard, Bruno; Baptiste, Pierre. "A survey of models and algorithms for emergency response logistics in electric distribution systems. Part I: Reliability planning with fault considerations", Computers \& Operations Research, 40.7(2013): 1895-1906.

[22] Perrier, Nathalie, et al. "A survey of models and algorithms for emergency response logistics in electric distribution systems. Part II: Contingency planning level", Computers \& Operations Research40.7(2013):1907-1922.

[23] CHEN Chao-mei, CHEN Yue, LIANG Yong-xia. "Citespace II: detecting and visualizing emerging trends and transient patterns in scientific literature", Jounal of the china society for scientific and technical information 28.3(2009): 401-421.

[24] LIU Ze-yuan,CHEN Li-xin. "Knowledge Visualizing Analysis in International Logistics Research", Library and Information Service 54. 08(2010): 140-130.

[25] CHEN Shi-ji. "Survey of Approaches to Research Front Detection", Modern Technology of Library and Information, 2009,(9):28-33.
[26] Haghani, Ali, and S. C. Oh. "Formulation and solution of a multicommodity, multi-modal network flow model for disaster relief operations", Transportation Research Part A Policy \& Practice, 30.3(1996):231-250.

[27] Fiedrich, F., F. Gehbauer, and U. Rickers. "Optimized resource allocation for emergency response after earthquake disasters", Safety Science 35.1(2000):41-57.

[28] Barbarosogu, G., and Y. Arda. "A two-stage stochastic programming framework for transportation planning in disaster response", Journal of the Operational Research Society volume 55.1(2004):43-53(11).

[29] 00zdamar, Linet, E. Ekinci, and B. Kü04ükyazici. "Emergency Logistics Planning in Natural Disasters", Annals of Operations Research 129.1-4(2004):217-245.

[30] Yi, Wei, and L. 00zdamar. "A Dynamic Logistics Coordination Model For Evacuation And Support In Disaster Response Activities", European Journal of Operational Research 179.3(2007):1177-1193.

[31] Sheu, Jiuh Biing. "An emergency logistics distribution approach for quick response to urgent relief demand in disasters", Transportation Research Part E Logistics \& Transportation Review, $\begin{array}{llll}\text { vol. } & 43.6 & \text { (2007): }\end{array}$ 